\title{
ACTION ROVINJ-A MODEL OF A SUPRAREGIONAL AFTER CARE SPINAL CORD INJURED PERSONS*
}

\author{
By A. Th. Terbizan \\ RZ-Tobelbad/Graz der AUVA-Austria.
}

The Austrian Workers Compensation Board (AWCB), an Accident Insurance Institute for about 2.5 million employed persons and $\mathrm{I} \cdot 4$ million pupils and students maintains several accident hospitals and rehabilitation centres. Two of these centres specialise treating paraplegic and tetraplegic patients. To obtain better rehabilitation, the Vienna municipality decided to buy the hospital near Rovinj (Republic Croatia/Yugoslavia), which now has some 300 beds.

The mild Mediterranean climate and facilities for long time rehabilitation for paraplegics already discharged from other centres were the crucial points for the AWCB contracting for 50 beds and a separate department belonging to the Orthopaedic Hospital of Rovinj in I97I.

From May until October spinal cord injured persons insured with the AWCB receive treatment on the Adriatic coast for an average duration of 2 I days. This 'Action Rovinj' gives tetraplegic and paraplegic patients the chance for at least once a year to escape from the monotony at home and/ or to give their relatives at home a much needed rest.

The 'Active Course Rovinj', which has nothing to do with the Action Rovinj, is another step to improve the rehabilitation possibilities. The Active Courses are mainly for tetraplegic patients, who are discharged from the centres in four or five weeks.

These courses give tetraplegic patients comprehensive and adequate training to acquire the final finess for the activities of daily living and for psychological stability. The rehabilitation programme is equivalent to the programme in the centres but more comprehensive with more self-care activities.

All the facilities of the Orthopaedic Hospital of Rovinj are available for all handicapped persons irrespective of nationality. Arrangements for accommodation and treatment (single or in groups) can be made directly with the authorities of the hospital in Rovinj.

$\star$ Summary of paper read at the Annual Meeting of the International Medical Society of Paraplegia, Stoke Mandeville, July I98I. 